\title{
Joseph Famerée (dir.), Vatican II comme style. L'herméneutique théologique du Concile
}

Paris, Éditions du Cerf, coll. «Unam Sanctam », 2012, 320 p.

Nicolas de Bremond d'Ars

\section{(Q) OpenEdition}

\section{Journals}

Édition électronique

URL : http://journals.openedition.org/assr/26407

DOI : $10.4000 /$ assr. 26407

ISSN : $1777-5825$

Éditeur

Éditions de l'EHESS

Édition imprimée

Date de publication : 31 décembre 2014

Pagination : 184

ISBN : 978-2-7132-2467-6

ISSN : 0335-5985

\section{Référence électronique}

Nicolas de Bremond d'Ars, « Joseph Famerée (dir.), Vatican II comme style. L'herméneutique

théologique du Concile », Archives de sciences sociales des religions [En ligne], 168 | 2014, mis en ligne le 17 avril 2015, consulté le 22 septembre 2020. URL : http://journals.openedition.org/assr/26407 ;

DOI : https://doi.org/10.4000/assr.26407

Ce document a été généré automatiquement le 22 septembre 2020

(C) Archives de sciences sociales des religions 


\section{Joseph Famerée (dir.), Vatican II comme style. L'herméneutique théologique du Concile}

Paris, Éditions du Cerf, coll. « Unam Sanctam », 2012, 320 p.

Nicolas de Bremond d'Ars

\section{RÉFÉRENCE}

Joseph Famerée (dir.), Vatican II comme style. L'herméneutique théologique du Concile, Paris, Éditions du Cerf, coll. « Unam Sanctam », 2012, 320 p. 
1 L'ouvrage collectif qui nous est proposé est construit sur une proposition du jésuite américain John W. O'Malley en 1991 qui entendait le Concile Vatican II, à partir du style rhétorique de sa production écrite. Plus exactement, l'hypothèse émise par O'Malley est que l'on doit prendre en compte l'énonciation dans sa singularité pour apprécier la nouveauté du concile. Il rappelle que le concile s'est voulu, selon la convocation de Jean XXIII, «pastoral», et qu'à le vouloir «doctrinal» ou «dogmatique» (même si des constitutions sont déclarées dogmatiques), on manque l'objectif - et donc, l'interprétation - du Concile Vatican II. L'ouvrage présenté par Joseph Famerée est le fruit du troisième colloque $\mathrm{du}$ Groupe international de recherche sur l'herméneutique de Vatican II.

2 Il va de soi que l'exercice présenté dans

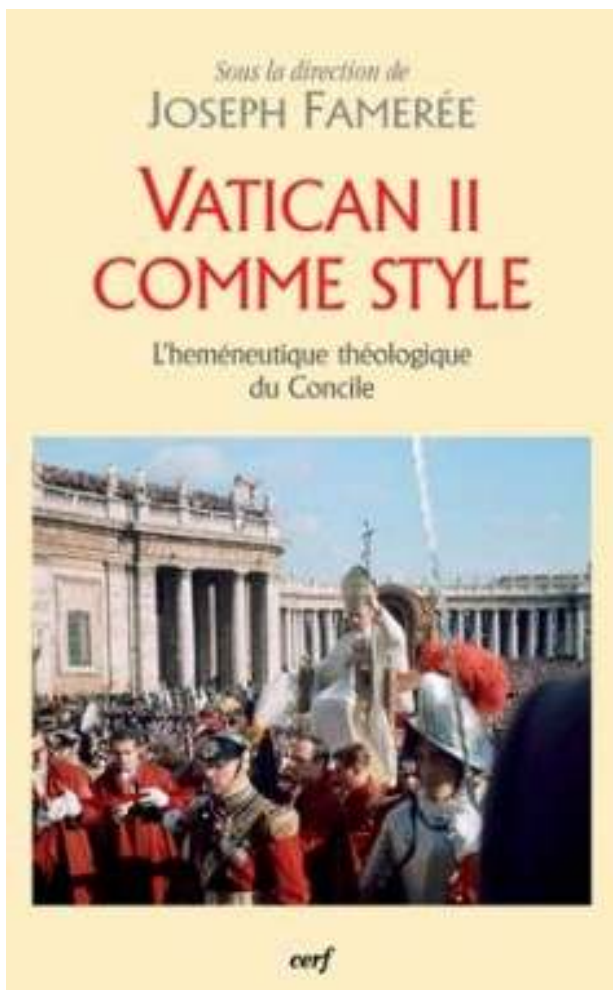
ces pages relève de la théologie. À ce titre, nous pourrions nous contenter de nous situer en extériorité par rapport à des problématiques qui concernent au premier chef l'interne du groupe catholique. Malgré tout, il n'est pas inintéressant pour le sociologue d'examiner comment le recours aux sciences sociales et humaines informe le travail théologique. Sur ce point, outre la démarche d'O'Malley qui revendique explicitement une approche rhétorique - il est spécialiste d'Érasme et de la littérature de la Renaissance - nous repérons bien comment l'objet « concile » est peu à peu construit à l'aide d'une problématisation de type politique : en quoi Vatican II dérange-t-il le processus conciliaire classique et, par là, le fonctionnement même de l'Église catholique romaine?

3 Les recherches sont présentées en trois parties. La première intitulée «Le style en éthique » se compose de trois contributions. La deuxième partie aborde "le style en ecclésiologie», avec six articles. La troisième porte sur «le style en théologie fondamentale ", composée de trois articles. Une conclusion clôt l'ensemble, en s'inspirant des débats du colloque.

Guy Jobin (I, 1) rappelle les fondements de l'interprétation en termes de rhétorique. Les travaux d'O. Reboul, C. Perelman ou B.Garsten (parmi d'autres) permettent de déborder quelque peu la position austinienne de l'illocutoire. Penser un concile comme style, c'est porter attention au projet d'énonciation du divin dans une visée qui peut s'avérer juridique, comme dans les conciles précédents (Trente, Vatican I), soit épidictique (panégyrique). Déconstruisant finement la variété des styles rhétoriques, tant de textes conciliaires que de documents ultérieurs, Jobin conclut par une requête de modestie : un style peut-il être porté au-delà de son contexte d'énonciation ?

5 La réflexion d'E. Gaziaux (I, 2) sur le style d'une éthique selon Vatican II semble moins convaincante. Si on perçoit l'affrontement de deux possibles éthiques, on ne voit guère comment la posture rhétorique analysée par Jobin précédemment retentit sur 
l'éthique. À lire Walter Lesch (I, 3), on comprend en effet que la notion de style fermement circonscrite par Jobin peine à s'appliquer à la dimension éthique. Avec Lesch et Gaziaux, le lecteur est immanquablement ramené de la rhétorique à un contenu propre de l'éthique.

Difficulté ressentie aussi par Dominique Barnérias, qui analyse «la paroisse comme style » (II, 1) : ici, le style est plutôt une configuration institutionnelle ou relationnelle. Peut-être pourra-t-on regretter, dans cet article, une certaine idéalisation des pratiques paroissiales, qu'une méthodique étude concrète permettrait de mieux étayer. Au-delà de l'éthique et de l'institutionalité paroissiale, G. Routhier (II, 3) s'interroge sur la possibilité d'user de la notion de style pour la figure concrète de l'évêque : concept pertinent? La réponse de l'auteur, malgré une belle analyse de l'évolution de la figure épiscopale, nous paraît négative. P. De Mey s'interroge, pour sa part, sur le «style œcuménique » de Vatican II (II, 5), sans échapper au piège de la confusion entre concept et contenu cognitif.

7 Il faut arriver à l'article de L. Villemin (II, 2) pour élargir et approfondir le concept de style, à partir des travaux du théologien C. Theobald (auteur de la contribution III, 3). Le style se réfère ici, au-delà de la production conciliaire, à la vie de Jésus-Christ comme style. C'est une posture éminemment singulière, qui donne naissance, après la nonécriture qui caractérise le fondateur du christianisme, à un style d'écrits (Évangiles) rompant avec les styles antérieurs. Le style est donc inscrit à la fois comme mode de vie et comme production écrite, indissociables l'un de l'autre. Ainsi se trouve justifié le recours à l'épithète " pastoral » pour définir Vatican II. L'expérience concrète revient donc au premier plan, et avec elle l'émergence du sujet (trois principaux: Dieu, l'individu croyant, le groupe ecclésial) et son historicité. Selon Villemin, le déploiement dans l'ecclésiologie de la question du style ouvre le regard sur la genèse du sujet ecclésial dans l'histoire concrète, loin d'une modélisation idéal-typique. A. JoinLambert, qui présente une fine description analytique des synodes diocésains (II, 6), rejoint L. Villemin lorsqu'il tend à montrer que le synode dans sa production écrite (actes synodaux) donne à voir un certain état du mode de vie pratique de l'Église diocésaine. Ici, la notion de style comme posture rhétorique performative est pertinente. Les deux auteurs sont rejoints par J. Famerée (également introducteur du volume) qui montre la dimension politique du style (II, 4). En comparant la production conciliaire et deux instructions romaines de 1992 et 2000, il révèle le bras de fer entre un groupe ecclésial «pastoral» (les Pères conciliaires) et un appareil administratif (la Curie romaine) qui s'efforce de réaffirmer ses prérogatives.

Une troisième partie de l'ouvrage examine la portée de la notion de style, tant phénoménologique que rhétorique, en théologie fondamentale. F. Nault (III, 1) déploie l'apport de l'exégète jésuite $P$. Beauchamp à l'analyse stylistique de textes du concile. Ce dernier plaide pour un acte d'écriture qui serait une kénose, ou une incarnation en direction du prochain, à l'image de la Révélation divine prenant parole des paroles humaines. Thème qui fait l'objet du travail d'O. Riaudel (III, 2). Celui-ci interroge la constitution conciliaire Dei Verbum et la manière dont elle tente d'articuler la révélation, la parole divine et le texte.

Dans le dernier article, $C$. Theobald est amené à déployer sa conception du style conciliaire de Vatican II. Il cherche à dépasser à la fois la dimension "événement de langage ", de rhétorique, qu'o'Malley a mise en place, et la dimension événementielle de l'École de Bologne, pour montrer comment ce style si particulier, qu'il retrouve dans 
les textes, relève aussi d'une façon, pour les Pères conciliaires, de "procéder et de se mettre d'accord» (p. 269). Autrement dit, « un deuxième niveau, le corpus conciliaire est-il la trace d'un gigantesque processus d'apprentissage individuel et collectif, d'une sorte de retour sur soi de la conscience ecclésiale aux prises avec la modernité et d'autres forces spirituelles et religieuses, trace d'une véritable "réforme" ou "conversion", certes inachevée, mais fondée dans l'Évangile même de Dieu " (p. 275-276). On le pressent, Theobald confine, dans la question du style, avec le processus économique intrinsèque à la définition de la relation Hommes-Dieu.

Bien que tourné vers une problématique interne au catholicisme romain, cet ouvrage décrit assez justement comment l'intuition construite autour de l'idée de style peut devenir un concept heuristique utile pour décrypter les enjeux sociaux de Vatican II. Concept qui tente d'établir une continuité entre un mode d'accès à une vérité, la façon dont elle se médiatise concrètement par le débat et le style littéraire qui l'exprimera au plus près de la double source, Bible et Tradition. Il serait intéressant de transposer une telle méthode au-delà du catholicisme, soit vers d'autres familles religieuses également productrices de textualité, soit, pourquoi pas, en direction des analyses sociales. 